socially isolated, unemployed and with poor social skills. Numbers of men and women were approximately equal. Men tended to have a shorter length of illness, shorter hospital admissions and were younger on transfer to the Vron. In this study there was a higher proportion of younger male schizophrenic patients and older women with affective disorders as in the survey by Clifford et al (1991). Over the seven year period the average ages and lengths of hospital admissions decreased steadily, particularly for men as the old long-stay group were replaced by a group at an earlier stage of their hospital careers. In-patient numbers of Gloucestershire's large mental hospitals Coney Hill and Horton Road fell from 1,427 in 1960 to 406 when Horton Road closed in 1988. Coney Hill is scheduled for closure in 1994 and had 271 beds on 31 December 1991. On a census date of 26 September 1990 Coney Hill hospital had only a small residuum of 16 in-patients without dementia with a stay of greater than one year (Anstee, 1991).

The Vron's target maximum length of stay of 18 months was only exceeded twice and $80 \%$ of residents were able to leave directly for placements in the community. The majority of residents have so far avoided further hospital admissions. The remaining $20 \%$ have subsequently been placed outside hospital.

The government continues to encourage the development of hospital hostels as part of the community care policy in providing treatment for those with long term and severe mental health problems (Department of Health, 1992). The combination of a short-stay rehabilitation hostel utilising a domestic setting in the community, backed up by a well developed supported lodgings scheme and range of group homes with a further 46 placements in six long-stay rehabilitation hostels, has allowed many of Gloucestershire's more disabled psychiatric patients to avoid becoming first 'new' and then 'old' long-stay hospital patients.

\section{Acknowledgement}

I wish to thank Dr B. H. Anstee for his invaluable suggestions and encouragement.

\section{References}

ANSTEE, B. H. (1992) The residuum of a traditional psychiatric hospital. Psychiatric Bulletin, 15, 666-667.

Clifford, P. Charman, A. Weba, Y. \& Best, S. (1991) Planning for community care. Long stay populations of hospitals scheduled for rundown or closure. British Journal of Psychiatry, 158, 190-196.

Department OF Health (1992) Residential Needs for Severely Disabled Psychiatric Patients: the Case for Hospital Hostels. HMSO (ISBN 0-11-321451-0).

- \& Soctal Security (1975) Better Services for the Mentally Ill. Cmnd 6233. HMSO: London.

HewEtT, S. \& Ryan, P. (1975) Alternatives to living in psychiatric hospitals - a pilot study. British Journal of Hospital Medicine, 14, 65-70.

\title{
Directory of staff training resources on the management of violence and aggression
}

The Multi-Sectoral Interest Group on Violence and Aggression Management Training has received several enquiries on the availability of local staff training in dealing with violence to staff. We would like to produce a directory of local courses and training packs (videos, workbooks etc.) which could be issued in response to enquiries. The directory could also be used by researchers wishing to contact those involved in training.
We would be pleased to hear about courses or training resources available anywhere in the UK. Any groups or individuals who wish to be included in the directory should contact Dr Cameron Stark, Department of Public Health, Ross House, Hawkhead Road, Paisley, PA2 7BN for a registration form. No fee is payable, and the directory will be made available at cost when it is completed. 